\title{
DESIGNATION OF TYPE SPECIES FOR HANA (HANIDAE, MEGASECOPTERA) ${ }^{*}$
}

\author{
By Jarmila Kukalova-Peck
}

Department of Earth Sciences

Carleton University, Ottawa, Ont. K1S 5B6, Canada

I inadvertently established the genus Hana without designating a type species (Kukalova-Peck, 1975, p. 6). Thus, the genus Hana and the family name Hanidae are not valid in accordance with article 13 of the International Code of Zoological Nomenclature (1985, p. 37). With this note I wish to designate $H$. filia KukalovaPeck, 1975, as the type species of the genus Hana to validate the generic and family names.

I thank Professor F. M. Carpenter for bringing this oversight to my attention and for allowing me to correct the problem.

\section{REFERENCE}

KuKalova-Peck, J.

1975. Megasecoptera from the Lower Permian of Moravia. Psyche 82(1): $1-19$.

\footnotetext{
${ }^{*}$ Manuscript received by the editor August 8, 1991.
} 

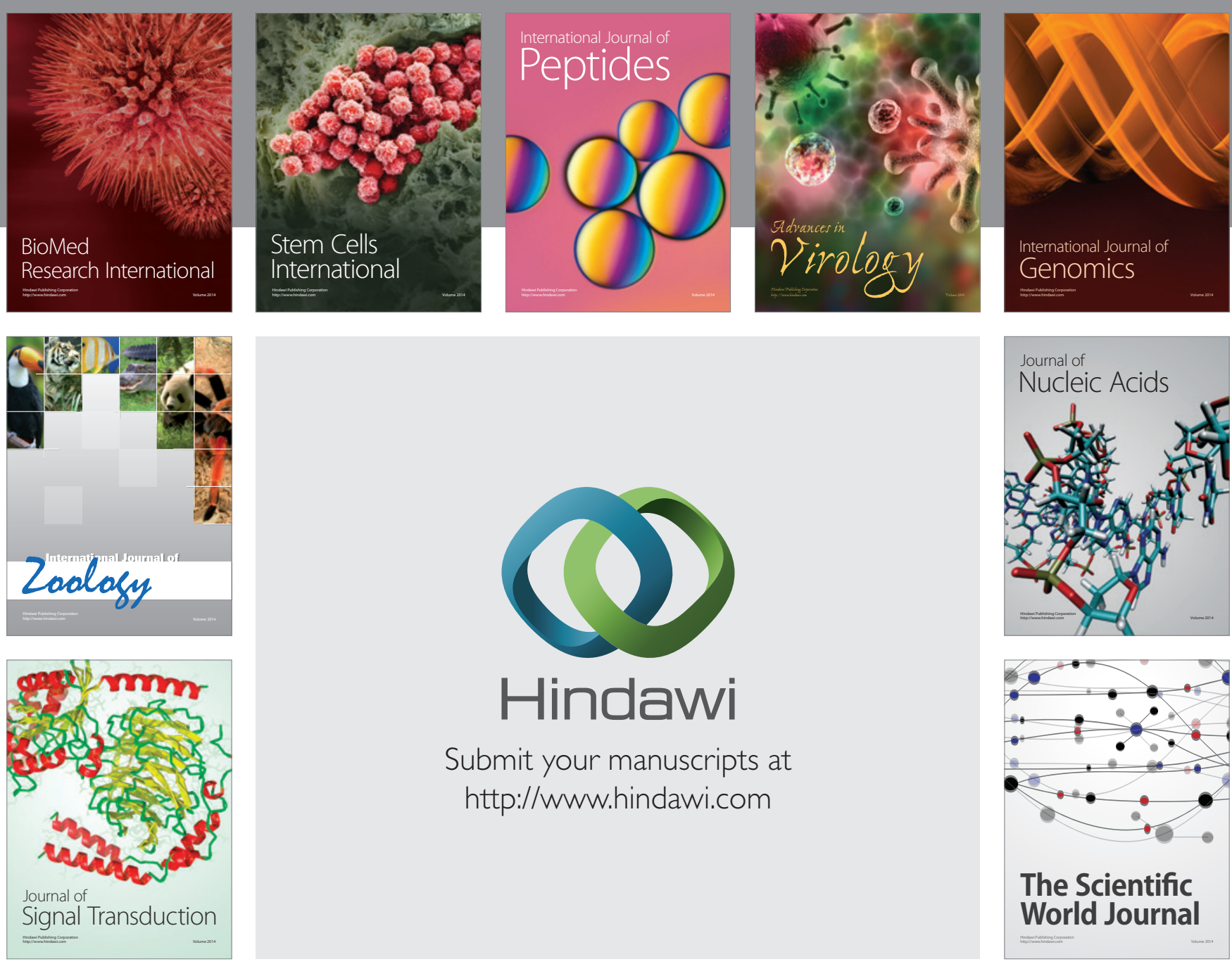

Submit your manuscripts at

http://www.hindawi.com
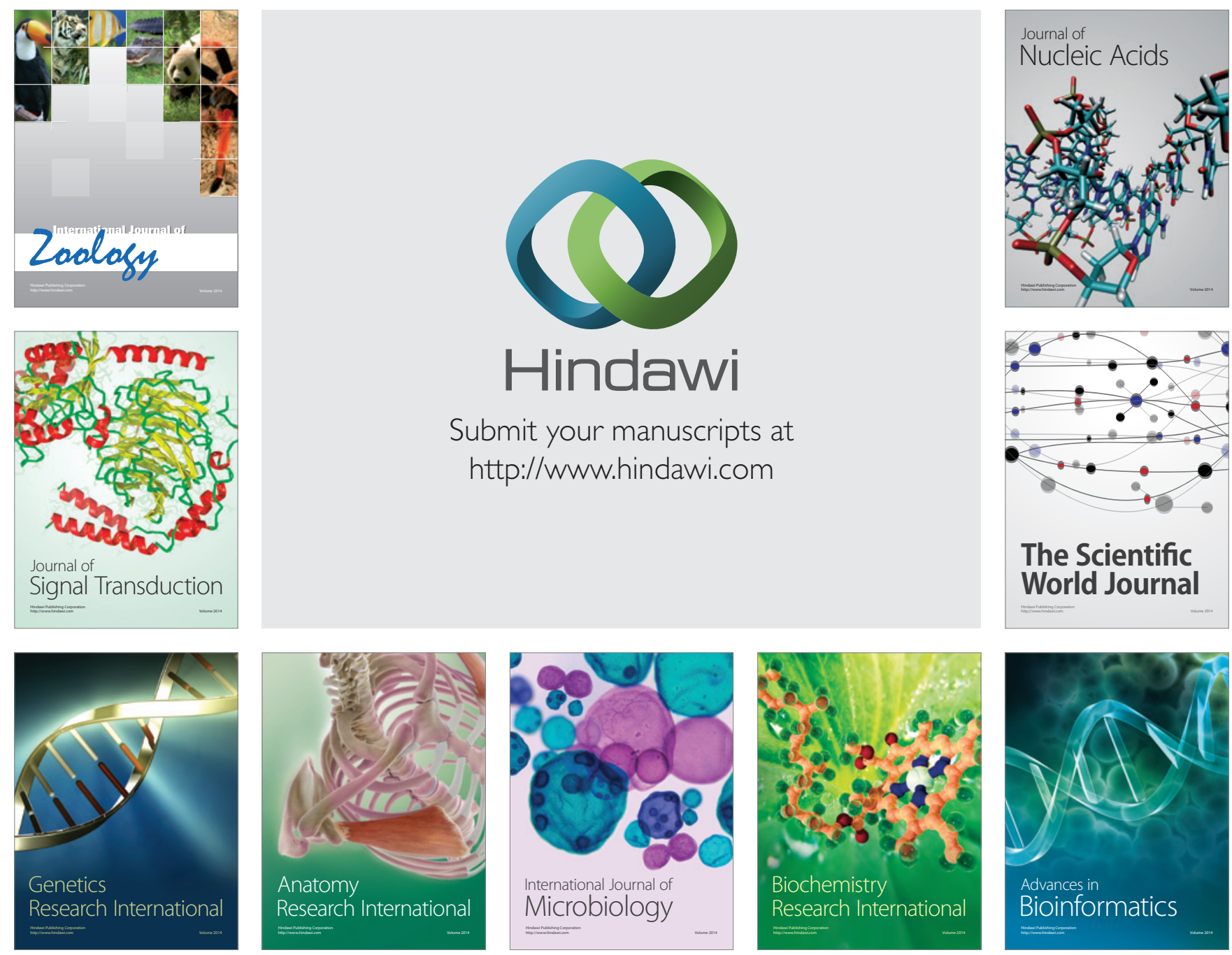

The Scientific World Journal
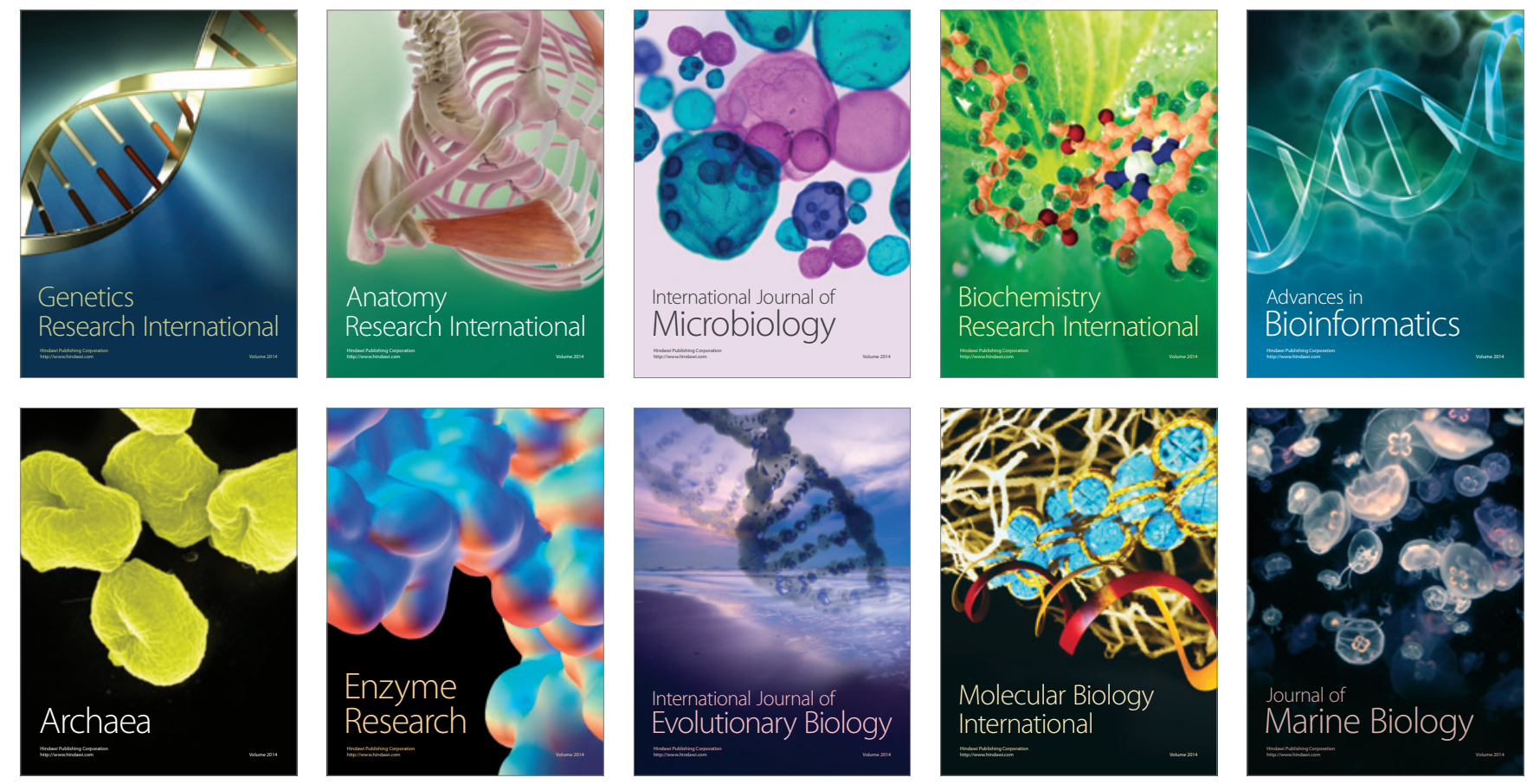